\title{
Truth concealed behind "Zero Increase of Total Water Use" and coordination approach of socio-economic and eco- environmental water uses in the Weihe River Basin, China
}

\author{
YANGWEN JIA ${ }^{1,2}$, NA WEI ${ }^{1,2}$, CHUNFENG HAO ${ }^{1,2}$, JINJUN YOU $^{1,2}$, \\ CUNWEN NIU ${ }^{1,2} \&$ YAQIN QIU ${ }^{1,2}$
}

1 State Key Laboratory of Simulation and Regulation of Water Cycle in River Basin, China Institute of Water Resources and Hydropower Research, 1 Yu-Yuan-Tan South Road, Beijing 100038, China jiaywl@iwhr.com, ywjia@yahoo.com

2 Department of Water Resources, China Institute of Water Resources and Hydropower Research, 1 Yu-Yuan-Tan South Road, Beijing 100038, China

\begin{abstract}
The water resources situation in the water-stressed Weihe River Basin, China, is more serious now than ever before because of a decrease in water resources and socio-economic development. A "Zero increase of socio-economic water use" in recent years gives people a wrong understanding and conceals the water crisis in the basin because the socio-economic water consumption has actually increased. Water use for the hydroecological system has been greatly reduced by a decrease in water resources and socio-economic water consumption increase. New concepts of hierarchical water uses for every sector and water consumption control are suggested for coordinating water uses of the socio-economy and ecosystems in the water-stressed basin. The traditional water resources allocation and regulation in China usually set up a priority sequence for water use sectors. Generally speaking, domestic water use has the highest priority and a highest guarantee rate, followed by industrial water use, irrigation and lastly ecological water use. The concept of hierarchical water use for every sector is to distinguish the water use of every sector into minimum part, appropriate part, and expected extra part with different guarantee rates, and the minimum parts of all sectors should be first guaranteed. By applying a water allocation model, we compared the water allocation results of the traditional approach and the newly suggested approach. Although further study is desired, the results are believed to be of an important referential value to sustainable development in the basin.
\end{abstract}

Key words water use; Weihe River; socio-economic water use; eco-environmental flow

\section{INTRODUCTION}

The Weihe River is the biggest tributary of the Yellow River. It originates from the Niaoshu Mountain of Weiyuan County, Gansu Province, and flows into the Yellow River in Tongguan County of Shaanxi Province. The total catchment area of the Weihe River is $134800 \mathrm{~km}^{2}$ with $50.1 \%, 44.1 \%$ and 5.8\% inside Shaanxi Province, Gansu Province, and Ningxia Hui Autonomous Region, respectively. With the rapid development of the economy and society along the river since the $1980 \mathrm{~s}$, the river has been suffering from various problems, including water resources insufficiency, water pollution, severe water channel blockage and frequent flooding.

In the past 30 years, annual average total water use in the Weihe River Basin was 6 billion $\mathrm{m}^{3}$, no big change in spite of some fluctuation, which is also called "Zero increase of socio-economic water use" by many people. Annual average agricultural water use is 3.9 billion $\mathrm{m}^{3}$ (accounting for about $2 / 3$ of the total water use), showing a declining trend, whereas industrial and domestic water uses increased (see Fig. 1). Annual river discharge at the Huaxian station (i.e. outflow into the Yellow River) shows a declining trend over the past 30 years, with the maximum of 13.1 billion $\mathrm{m}^{3}$ in 1983, and the minimum of 1.68 billion $\mathrm{m}^{3}$ in 1997 (see Fig. 2). Water use discussed in this paper is defined as the total volume of fresh water drawn from the natural water cycle that is used to produce goods and services, instead of using water footprint as a consumption indicator of water use (Hoekstra, 2007).

Based on water balance theory, annual water consumption WC can be calculated according to the following equation:

$$
\mathrm{WC}=\mathrm{WR}-\mathrm{Q}
$$

where WR represents annual water resources and Q is annual discharge at the Huaxian station. The over-exploited groundwater is neglected in this study because its estimated annually-averaged 
value is about 0.2 billion cubic metres (the Ministry of Water Resources, 2011), much smaller than WR and Q.

The water consumption analysis result is shown in Table 1. Comparing outflow into the Yellow River during the 1980s and 2000s, it decreased much more than water resources. Based on the water balance result, water consumption increased, but water use did not.

In summary: (1) water resources situation in the water-stressed Weihe River Basin is more serious now than ever before because of water resources decrease and socio-economic development; (2) zero increase of socio-economic water use gives people a wrong conception and conceals the water crisis in these regions; (3) water use for the hydro-ecological system has been greatly reduced by a decrease in water resources and an increase in socio-economic water consumption. Therefore, a new concept and approach for water resources allocation may be desired for coordinating water uses of socio-economy and ecosystems in the water-stressed region.

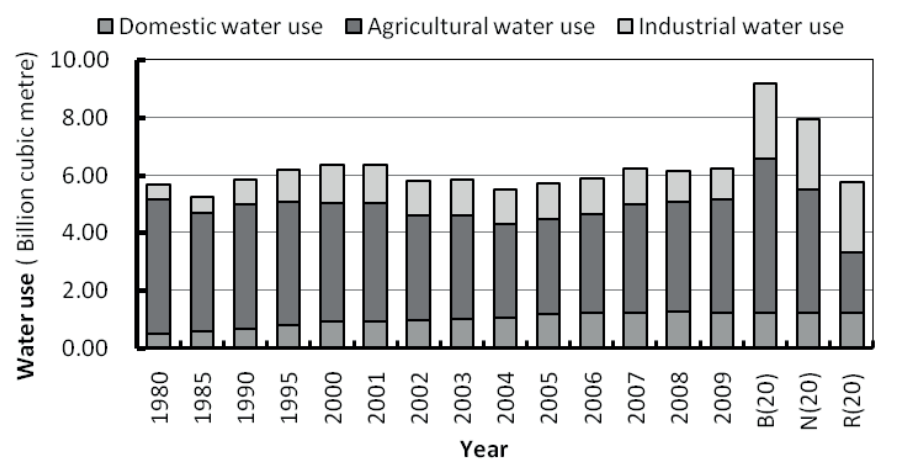

Fig. 1 Water use change in the Weihe River Basin.

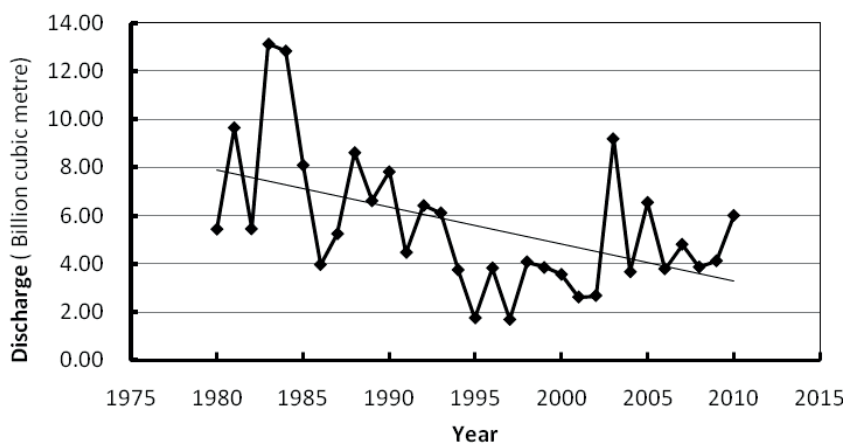

Fig. 2 Annual discharge change at Huaxian station in the Weihe River Basin.

Table 1 Water consumption analysis.

\begin{tabular}{llll}
\hline & $\begin{array}{l}\text { Water resources } \\
(\text { BCM/year) }\end{array}$ & $\begin{array}{l}\text { Outflow into YR } \\
(\text { BCM/year) }\end{array}$ & $\begin{array}{l}\text { Water consumption } \\
\text { (BCM/year) }\end{array}$ \\
\hline $1980 \mathrm{~s}$ & 11.98 & 7.91 & 4.07 \\
$2000 \mathrm{~s}$ & 9.06 & 4.49 & 4.57 \\
change ratio & $-24 \%$ & $-43 \%$ & $12 \%$ \\
\hline
\end{tabular}

\section{METHODS}

The main idea is as follows: (1) using the newly-suggested concept of hierarchical water use to do the water demand prediction for future planning years, and comparing the results with those of the traditional method; (2) establishing the water resources allocation model (ROWAS) for the simulation of various scenarios; (3) demonstrating the effect of the newly suggested hierarchical water use concept on coordinating socio-economic water use and ecological water use through scenario analysis. In this section, the concept of hierarchical water use and the ROWAS model are 
described, and the scenario setting and minimal eco-flow constraints consideration are referred to in the next section.

\section{Concept of hierarchical water use}

The principle of water use priority can be complex for different regions related to government policy and water system capacity. The traditional water resources allocation and regulation usually set up a priority sequence for water use sectors. Generally speaking, domestic water use has a top priority and a highest guarantee rate, next is industrial water use, followed by irrigation and lastly ecological water use. Within this context, eco-environmental flow in dry regions is usually difficult to satisfy. Hence, the concept of hierarchical water use is put forward, which distinguishes the water use of every sector into a minimum part, appropriate part, and expected extra part with different guarantee rates, especially for irrigation water use and ecological water use. The utility cost function is considered for decision making of hierarchical water use in each sector, which includes the correlativity between water use and corresponding utility, as well as cost. Meanwhile, optimization for the process of water use in each sector can significantly affect the utility and water productivity because of various characteristics of sensitivity to water in different stages.

Figure 3 illustrates a general relationship between water use and utility, as well as cost for a certain sector. Within the utility function, $\mathrm{W}_{0}$ represents the least water demand for a probable positive utility, while $\mathrm{W}_{\max }$ represents water use for the maximum utility. If insufficient water is applied in a certain sector, it may result in low-quality or even totally loss of utility. Taking irrigation water as an example, a crop will be wiped out by drought unless a considerable amount of water is added. Once a minimum amount of water is guaranteed, the utility begins to increase with water use. At the first part of utility function, the relationship between water use and utility may be roughly linear and then begins to curve over near the peak, reflected in the section between $\mathrm{W}_{0}$ and $\mathrm{W}_{\max }$. It has been revealed in agriculture research that the crop yield increase per unit water could be held constant up to approximately $50 \%$ of full irrigation and gradually levels off after that (Geerts and Raes 2009). The second part of utility function indicates that too much water more than $\mathrm{W}_{\max }$ applied, may reduce utility as a result of excess of system usage. While in the cost function, it is often generalized to be linear with a positive vertical intercept representing upfront investment, as well as the upper limit shown as the design capacity $\mathrm{W}_{\text {cap }}$ (English 1990). By synthesizing the utility and cost function, net revenue function can be acquired. There are two points for balance of utility and cost, $\mathrm{W}_{\min }$ and $\mathrm{W}_{\mathrm{exc}}$, and water use between them always brings positive net revenue. It is worth noting that the maximum net revenue is achieved by $\mathrm{W}_{\text {eff }}$ between $\mathrm{W}_{\min }$ and $\mathrm{W}_{\max }$, where the marginal utility equals the marginal cost.

In this paper we distinguish the water use of every sector into minimum part, appropriate part, and expected extra part. $\mathrm{W}_{\min }$, a balance point of utility and cost function, with relatively little water use, is regarded as minimum part of water use, taking account of its practical feasibility compared with $\mathrm{W}_{0}$. The peak point of utility function $\mathrm{W}_{\max }$ is eligible for the expected extra part of water use as the maximum water use for positive marginal utility. Also, $\mathrm{W}_{\text {eff }}$ between $\mathrm{W}_{\min }$ and $\mathrm{W}_{\max }$ in accordance with maximum net revenue serves as the appropriate part of water use in view of profitable operation in practice and considerable utility follows.

Among different sectors of water use, including domestic water use, irrigation water use, industrial water use and ecological water use, the minimum parts of all sectors should be first guaranteed in the first stage of priority sequence. The second stage of priority sequence would be greatly distinct for regions under different levels of development in consideration of diverse government policies and pressing development needs. In the water-stressed Weihe River Basin, China, the second stage of priority sequence in principle is as follows: appropriate and expected extra domestic water use are the most important, followed by appropriate industrial and irrigation water use, then extra industrial and irrigation water use, and lastly appropriate and expected ecological water use.

For the complexity of hierarchical water use for different sectors, the paper selectively analyses hierarchical classification of irrigation water use in the Weihe River Basin, China. The 


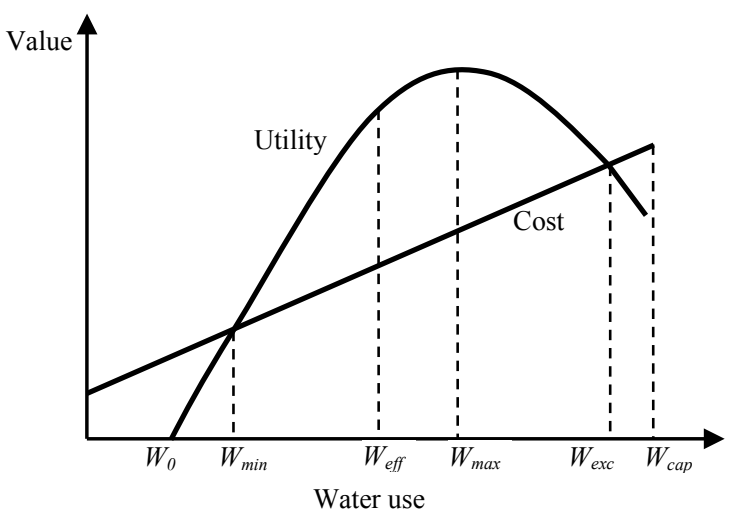

Fig. 3 General shape of utility and cost function of water use (modified based on English 1990).

apportionment of irrigation water according to distinct sensitivity for each growth stage can significantly affect crop yields independently of the amount of water used (Kang et al. 2002). Irrigation water should be guaranteed as far as possible for the most critical stages of crop growth.

\section{ROWAS model}

The Rules based Object-oriented Water Allocation Simulation Model (ROWAS) is a system simulation model (You et al. 2005), which is based on macro-physical mechanism of water transport and transfer. The purpose of system design is to quickly provide reasonable answers for multi-stage, multi-level, multi-objective and multi-scheme water resources decision problems. The real water resource system is simplified based on the system generalization. By establishing various engineering constraints and system operation rules, the model can attain rational allocation of water resources from different water sources to different users. The core concept of ROWAS is to fulfil the conversion from reality to the mathematical description, and extract rules simulating water transfer process. The simulation process can be realized by decomposing system and programming using object-oriented technology. The model abides by seven regulation principles: security of system operation, coordination of multiuser water allocation, wide and shallow damage for water allocation, priority for users, observing current water allocation, high efficiency and fairness. Considering the influence of different factors, the rational allocation, on three levels of time, space and user, can be realized under the control of these seven principles.

In order to analyse the effects of hierarchical water use for different users on the overall water in the Weihe River Basin, according to the above assumption and method, the ROWAS model is established so as to solve the problems of water resources optimal allocation for a large complex system with water resource, society, economy and environment. On the basis of watershed characteristics and system generalization rules, the whole basin is divided into 27 calculating units by nesting the third-level water resources regions and administrative districts, consisting of 48 surface water conservancy projects, as well as more than 290 water transmission lines. Water supply outside river and water processes for control sections inside the river can be calculated with the 1956-2005 series of data for the Weihe River Basin.

\section{SCENARIOS AND RESULTS}

\section{Scenario setting and minimal eco-flow constraints}

Scenarios for water demand are as follows: (1) Traditional lump-sum water use for users: the scheme uses normal water-saving efforts as water demand prediction, which is also called general water-saving scheme, with scheme number $\mathrm{B}(20)$. (2) Hierarchical water use for users: based on the water-saving mode for status, hierarchical water use enlarges the adjustment for economic structure and water-saving technology. In addition, the concept of hierarchical water use is proposed. According to water demand characteristics for different crops in the key period in the Weihe River Basin, there are two scenarios for agricultural water, one is suitable water demand, 
which is also called strengthened water-saving scheme, with scheme number $\mathrm{N}(20)$; and the other is minimal water demand, which is also called minimal water demand scheme, with scheme number R(20). For the minimal water demand scheme, crops are only irrigated at critical growing periods, e.g. irrigation of wheat twice at sowing and heading periods and irrigation for maize once at sowing period. Domestic and industrial water demand is not graded due to the lack of classification basis.

Aiming to realize ecological protection and construction target in the Weihe River basin, the main stream of the Weihe River is divided into 24 ecological function zones, with 25 ecological control sections accordingly. The minimal eco-flow target of each control section is presented. This paper selects several typical control sections (see Table 2) to analyse the influence of different water adjustment schemes on water processes in the river.

The prediction of water demand for each scheme is shown in Table 3. It can be seen that in 2020 water demand for traditional lump-sum water use is the largest, about 9.28 billion cubic metres (BCM), with agriculture water demand of 5.32BCM. After adopting hierarchical water use, the water demand for strengthened water-saving scheme is $1.24 \mathrm{BCM}$ lower than the traditional lump-sum water use, with agriculture reduced by $1.05 \mathrm{BCM}$. The water demand for minimal water demand scheme is $3.41 \mathrm{BCM}$ lower than traditional single water use, with agriculture reduced by 3.22BCM.

Table 2 Control sections and the minimal eco-flow.

\begin{tabular}{lll}
\hline Ecological control section & $\begin{array}{l}\text { Ecological flow target } \\
\text { (Jan. to April) }\left(\mathrm{m}^{3} / \mathrm{s}\right)\end{array}$ & $\begin{array}{l}\text { Ecological flow target } \\
\text { (May to Dec.) }\left(\mathrm{m}^{3} / \mathrm{s}\right)\end{array}$ \\
\hline Lin Jiacun \#1 & 6.54 & 6.54 \\
Qian River \#4 & 6.54 & 12.6 \\
Stone River \#6 & 6.54 & 6.61 \\
Qishui River \#9 & 15.75 & 15.75 \\
\hline
\end{tabular}

Table 3 Water demand prediction for schemes (BCM).

\begin{tabular}{lllllllll}
\hline $\begin{array}{l}\text { Level } \\
\text { year }\end{array}$ & Schemes & $\begin{array}{l}\text { Total water } \\
\text { demand }\end{array}$ & Urban life & Rural life & Industry & Agriculture & $\begin{array}{l}\text { Urban } \\
\text { ecology }\end{array}$ & $\begin{array}{l}\text { Rural } \\
\text { ecology }\end{array}$ \\
\hline 2020 & $\mathrm{~B}(20)$ & 9.28 & 0.83 & 0.43 & 2.60 & 5.32 & 0.09 & 0.00 \\
& $\mathrm{~N}(20)$ & 8.04 & 0.80 & 0.43 & 2.44 & 4.27 & 0.09 & 0.00 \\
& $\mathrm{R}(20)$ & 5.87 & 0.80 & 0.43 & 2.44 & 2.10 & 0.09 & 0.00 \\
\hline
\end{tabular}

\section{RESULTS}

The balance of water demand-supply and supply structure for each scheme is shown in Table 4 and Fig. 1. As can be seen, in 2020 the water shortage for traditional lump-sum water use is 0.81 $\mathrm{BCM}$, with water deficient ratio 9\%; after adopting the concept of hierarchical water use, the balance of water demand-supply can be basically met. The water shortage is between 0.04 and $0.20 \mathrm{BCM}$, with water deficient ratio $2 \%$, and the water shortage for agriculture decreases markedly.

According to the analysis of water supply, water consumption and water discharge for schemes with different water conditions, the annual average flow and the flow of $75 \%$ frequency years at control sections can be calculated, as shown in Table 5. The monthly guarantee rate of the minimal eco-flow is shown in Table 6. As can be seen, after adopting hierarchical water use, the characteristic flows can be increased, and the monthly guarantee rate of the minimal eco-flow can also be increased.

\section{CONCLUSION}

Through the analysis of historical water use in the Weihe River Basin, it is found that the total water use showed no big change in spite of some fluctuation, which is also known as "Zero increase of socio-economic water use" by many people; however, this actually gives people a 
wrong conception and conceals the water crisis in these regions, because water use for the hydroecological system has been greatly reduced by water resources decrease and socio-economic water consumption increase.

A new concept of hierarchical water uses for every sector is suggested and the ROWAS water allocation model is adopted for coordinating water uses of socio-economy and ecosystems in the water-stressed basin. Through applying ROWAS, we compare the water allocation results of the traditional approach and those of the newly suggested approach. The results show that after adopting the newly suggested approach, the characteristic flows can be increased, and the monthly guarantee rate of the minimal eco-flow can also be increased, in addition to guaranteeing the minimal agricultural water use and industrial and domestic water use. Although a further study is desired, the results are believed to be of an important referential value to sustainable development decision-makings in the basin.

Table 4 Balance of water demand-supply (BCM).

\begin{tabular}{|c|c|c|c|c|c|c|c|c|c|}
\hline \multirow{2}{*}{$\begin{array}{l}\text { Level } \\
\text { year }\end{array}$} & \multirow{2}{*}{ Schemes } & \multicolumn{2}{|c|}{ Water demand } & \multicolumn{2}{|c|}{ Water supply } & \multirow[b]{2}{*}{$\begin{array}{l}\text { Ground } \\
\text { water }\end{array}$} & \multirow[b]{2}{*}{ Others } & \multicolumn{2}{|c|}{ Water shortage } \\
\hline & & Total & $\begin{array}{l}\text { Agricul- } \\
\text { ture }\end{array}$ & Total & $\begin{array}{l}\text { Surface } \\
\text { water }\end{array}$ & & & Total & $\begin{array}{l}\text { Agricul- } \\
\text { ture }\end{array}$ \\
\hline \multirow[t]{3}{*}{2020} & B (20) & 9.28 & 5.32 & 8.47 & 5.31 & 2.30 & 0.86 & 0.81 & 0.78 \\
\hline & $N(20)$ & 8.04 & 4.27 & 7.83 & 4.71 & 2.22 & 0.90 & 0.20 & 0.18 \\
\hline & $\mathrm{R}(20)$ & 5.87 & 2.10 & 5.83 & 3.33 & 1.57 & 0.93 & 0.04 & 0.02 \\
\hline
\end{tabular}

Table 5 Characteristic flows at control sections $\left(\mathrm{m}^{3} / \mathrm{s}\right)$.

\begin{tabular}{lllllll}
\hline Section name & B (20) & & N (20) & \multicolumn{3}{c}{ R (20) } \\
& Mean & $75 \%$ & Mean & $75 \%$ & Mean & $75 \%$ \\
\hline Lin Jiacun \#1 & 38.9 & 14.8 & 43.3 & 17.4 & 54.1 & 28.4 \\
Qian River \#4 & 43.5 & 16.7 & 49.2 & 19.3 & 64.2 & 34.9 \\
Stone River \#6 & 50.8 & 20.3 & 56.7 & 23.1 & 72.3 & 38.8 \\
Qishui River \#9 & 65.5 & 31.6 & 71.6 & 34.9 & 88.4 & 50.9 \\
\hline
\end{tabular}

Table 6 Monthly guarantee rate of minimal eco-flow (\%).

\begin{tabular}{llll}
\hline Section name & $\mathrm{B}(20)$ & $\mathrm{N}(20)$ & $\mathrm{R}(20)$ \\
\hline Lin Jiacun \#1 & 63.8 & 70.0 & 89.1 \\
Qian River \#4 & 68.8 & 74.7 & 91.8 \\
Stone River \#6 & 68.5 & 75.0 & 90.8 \\
Qishui River \#9 & 86.8 & 90.5 & 98.2 \\
\hline
\end{tabular}

Acknowledgement The research received financial support from the National Scientific Foundation of China (NSFC) Projects (50939006, 51379215), and the Project of Weihe Ecoenvironmental Flow and Regulation Guarantee Mechanism (Z0202042013).

\section{REFERENCES}

English, M. (1990) Deficit Irrigation. I: Analytical Framework. Journal of Irrigation and Drainage Engineering 116(3), 399412.

Geerts, S. and Raes, D. (2009) Deficit irrigation as an on-farm strategy to maximize crop water productivity in dry areas. Agricultural Water Management 96, 1275-1284.

Hoekstra, A. Y. and Chapagain, A. K. (2007) Water footprints of nations: water use by people as a function of their consumption pattern. Water Resources Management 21(1), 35-48.

Kang, S., et al. (2002) Effects of limited irrigation yield and water use efficiency of winter wheat in the Loess Plateau of China. Agricultural Water Management 55, 203-216.

The Ministry of Water Resources (2011) The China Water Resources Bulletin. Hydraulic Publishing, Beijing, China.

You, J., Gan, H. and Wang, L. (2005) A rules-driven object-oriented simulation model for water resources system [C]. Proc. of XXXI IAHR Congress, Seoul, Korea, Vol. C: 4493-4502. 